\title{
A manifestação do lugar nos versos do cururu na região paulista do Médio-Tietê
}

\author{
Henrique Albiero Pazetti
}

Mestrando em Geografia pela Unesp (Rio Claro).E-mail: henriquepazetti@gmail.com

Recebido em 04/2012. Aceito para publicação em 12/2012.

Versão online publicada em 01/02/2013 (http://seer.ufrgs.br/paraonde)

\begin{abstract}
Resumo: Analisar a relação do homem com o lugar e como esta afinidade é expressa na música, é a intenção primordial deste trabalho que faz parte de um projeto de pós-graduação. 0 viés fenomenológico em Geografia será o norteador deste processo. 0 recorte espacial será o interior do estado de São Paulo (mais precisamente a região do médio-Tietê) e sua expressão através do cururu. 0 cururu é uma manifestação folclórica típica de algumas cidades desta região e consiste numa disputa entre cantadores que versam sobre diversos temas ao som da viola caipira. Espera-se com este trabalho dar alguma contribuição no diálogo entre Geografia e música, bem como revalorizar tal manifestação cultural regional, tão importante para a identidade do povo que a vive.

Palavras-chave: Geografia. Lugar. Cururu.
\end{abstract}

\section{Introdução}

Este trabalho é parte de algumas reflexões que vem sendo feitas para o programa de pósgraduação (mestrado) em Geografia da Universidade Paulista Julio de Mesquita Filho, campus de Rio Claro. Ele tem como anseio principal analisar a relação do homem com o meio e sua expressão através da música, neste caso específico o foco será o cururu.

Nascido no processo de colonização realizada em nosso país principalmente pelos portugueses, o cururu é uma mistura da cultura ibérica (que trouxeram a viola de dez cordas, também chamada de caipira que é o principal instrumento neste evento) à rítmica indígena. Além de o cururu ser o nome de uma "batida mãe" na viola caipira (vindo dar origem a outras batidas executadas no instrumento) é um evento onde dois cantadores, acompanhados de violeiros duelam para uma platéia, seguindo a mesma rima (chamada de carreira) até o fim, se sagra vencedor aquele que conquistar o carisma da platéia com versos afiados e certeiros.

0 cururu se difundiu pela região paulista do médio Tietê através do movimento dos bandeirantes e tropeiros que fizeram o processo de interiorização do país. Ele é muito presente ainda enquanto manifestação artística regional. Em seus versos é possível perceber a relação íntima do homem com seu lugar, onde paisagens, amores, saudades, religiosidade e lembranças que não morrem ganham corpo na voz do cantador e no som da viola caipira, instrumento primordial neste evento.

0 viés fenomenológico presente na Geogra- fia Humanista norteará este trabalho. A Geografia Humanista surge como uma crítica à ciência positivista que sendo "dogmática, abstrata e estreita em sua abordagem [...]" (ENTRIKIN, 1980, p.21) deixa de lado aspectos importantes na relação do homem com o espaço geográfico. Diferenciando-se do espaço matemático, a Geografia Humanista compreende este (o espaço) como carregado de sentimentos e emoções, símbolos e imaginações, muito presentes na música, foco primordial neste trabalho.

\section{Música caipira e o cururu}

O Brasil é um país com enorme riqueza cultural e temos na música popular uma das expressões mais importantes do nosso povo. 0 hibridismo étnico que formou a população brasileira pode ser apontado como a principal razão da variedade musical encontrada no país, sendo a fusão de elementos indígenas, africanos e europeus a tônica formadora deste processo (MELLO apud ABREU, 2001).

A música denominada de caipira é uma vertente desta imensidão artística encontrada no Brasil e tem no solo paulista o seu berço, mais precisamente na região paulista do médio Tietê (NEPOMUCENO, 1999).

0 cerne de sua origem é a mistura de dois elementos principais, o índio e o europeu. Desde sua chegada ao Brasil o colonizador encontrou na música uma forma de cativar os índios no processo de catequização, influenciando assim, de modo contundente a formação cultural brasileira, bem como as identidades regionais, como no caso da região pa- 
ulista em questão (HOLLER, 2005).

A mistura da cultura ibérica com as tradições indígenas foi moldando o corpo da música caipira. A tradição musical dos índios, nos seus ritos e festas, era marcada pelas danças com forte ênfase rítmica, com o bater das mãos e pés, essa característica foi marcante na formação desta música juntamente com a viola, instrumento trazido para cá com os portugueses, utilizada para facilitar a catequização dos índios e também para preencher o tempo livre destes colonizadores. Como afirma NEPOMUCENO: "os primeiros cantos, na viola, foram os da catequese. Misturando-se melodias portuguesas às dos índios, crenças cristãs às danças pagãs, surgiram ritmos e gêneros, como o cururu e o cateretê" (p.56, 1999).

A viola logo começou a fazer parte do cotidiano dos primeiros habitantes de São Paulo, se tornando símbolo deste povo e da cultura denominada de caipira:

A identificação da viola com os primeiros habitantes da região de São Paulo e se fortaleceu na medida em que o tempo passou. $\mathrm{O}$ fato de encon-trarmos a viola na região da Paulis-tânia ${ }^{1}$ denota o quanto foi um instru-mento presente na cultura bandeiran-te e posteriormente tropeira a ponto de se firmar como elemento cultural nos espaços onde andaram e se fixaram as bandeiras (VILELA PINTO, p.8, 2008-2009).

Sendo assim, desta fusão dos elementos indígenas à cultura européia (tendo na viola seu principal instrumento) surgiram alguns ritmos musicais e danças que foram a base do desenvolvimento da música caipira, como o cururu. Podemos afirmar então que o cururu surgiu como uma adaptação a uma dança indígena, transformando-se em um canto religioso marcado pelas batidas de pé, utilizado pelos portugueses no processo de colonização (ARAÚJO, 1952; AMARAL PINTO 2008; VILELA PINTO, 1999, NEPOMUCENO, 1999).

O cururu se enraíza e se espalha pelo interior do estado de São Paulo principalmente através dos bandeirantes e tropeiros, que levaram consigo não somente cargas e produtos, mas também a cultura caipira, difundindo-a sertão adentro.

0 povoamento paulista foi condicionado pela atividade nômade exercida pelos bandeiran-tes que em busca de incorporação de terras à coroa, nos séculos XVI, XVII e XVIII desbravaram o sertão do estado de São Paulo e de partes do Brasil expandindo e formando sua cultura (CANDIDO, 1964). Euclydes da Cunha descreve em seu livro os Sertões, as características principais destes homens, chamados de paulistas (por mais que extrapolassem os limites territoriais do estado de São Paulo):

O paulista - e a significação histórica deste nome abrange os filhos do Rio de Janeiro, Minas, São Paulo e regiões do sul - erigiu-se como um tipo autônomo, aventuroso, rebelde, libérrimo, com a feição perfeita de um dominador de terra, emancipando-se, insurreto, da tutela longínqua, e afastando-se do mar e dos galeões da metrópole, investindo com os sertões desconhe-cidos, delineando a epopéia inédita das bandeiras... (CUNHA, 2000, p.73).

Os bandeirantes eram formados basicamente por descendentes de índios (fruto da fusão com o colonizador europeu) e os próprios indígenas. Levavam consigo não somente a herança genética de seus ancestrais, mas também a herança cultural. Posteriormente os tropeiros continuaram o desbravamento do sertão brasi-leiro, levando assim como os bandeirantes a música e a cultura caipira, visto que a viola era companheira inseparável destes homens, "cantar era a única diversão e o combustível moral na caminhada" (NEPOMUCENO, 1999, p.82).

Diversas cidades que foram fundadas neste processo de interiorização das bandeiras e tropas (que seguiram a rota do rio Tietê) têm o cururu muito presente enquanto manifestação artística regional, sendo parte da identidade de sua população. As principais cidades onde o cururu é encontrado são: Sorocaba, Tatuí, Botucatu e Piracicaba (figura 1).

Não somente o cururu, mas a música caipira original (produzida entre as décadas de 20 e 50 do século XX) que influenciou todo o desenrolar desta cultura faz parte de "um território específico: uma área de difusão a partir de um triângulo tendo por vértices as cidades paulistas de Piracicaba, Sorocaba e Botucatu" (RIBEIRO, 2006, p.40). 0 cururu é presente em uma região muito específica denominada de médio Tietê:

0 cururu é restrito, como desafio cantado, à região do médio Tietê. Prova disso é a história corrente no universo cururueiro de que um famoso cantador chegou a ser vaiado numa cidade do Vale do Ribeira por

${ }^{1} \mathrm{O}$ autor determina Paulistânia como: “toda a região povoada pelas bandeiras, região esta que coincide com as áreas de acomodação do que entendemos por cultura caipira, ou seja, São Paulo, Sul de Minas e Triangulo Mineiro, Goiás, Mato Grosso do Sul, parte do Mato Grosso, parte de Tocantins e norte do Paraná" (VILELA PINTO, p.27, 2008-2009) 


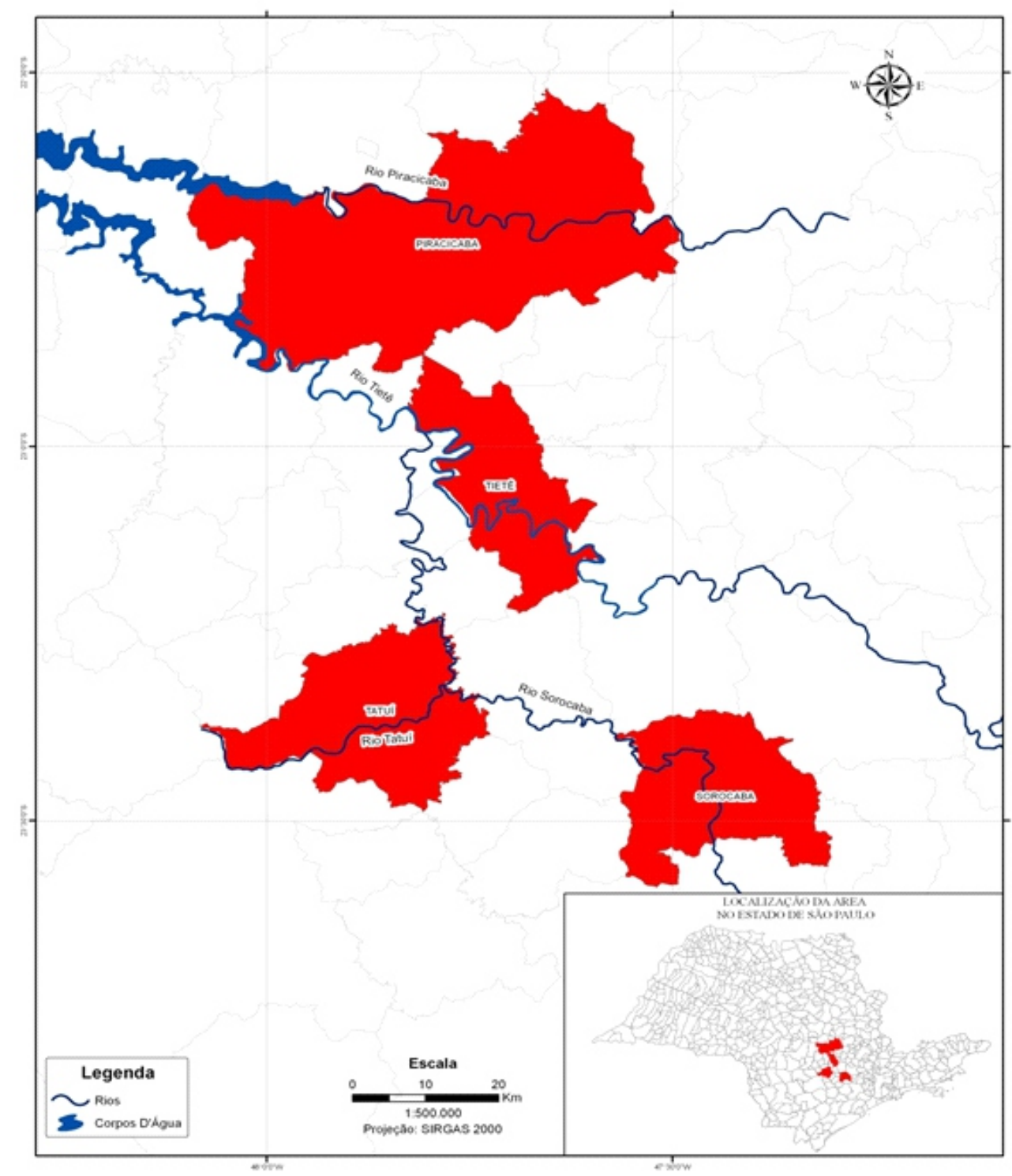

Figura 1- Mapa representando as principais cidades do médio Tietê com a manifestação cultural do cururu (Org. Eder Roberto Silvestre).

não conhecerem, os habitantes de lá, o cururu. E não há cururueiro que não sinta receio em cantar o cururu fora da sua área de abrangência (CAVALHEIRO, 2003, p.5).

Existem duas versões principais para determinar a origem do termo cururu, para alguns pesquisadores ele surgiu da dificuldade que os índios tinham em pronunciar a palavra cruz, assim ela foi se transformando até chegar ao termo cururu (OLIVEIRA apud VILELA PINTO, 1999, NEPOMUCENO, 1999; ANASTACIO, 2010). A outra versão afirma que o termo cururu se origina da palavra Kuru'ru (um tipo de sapo na linguagem tupi), pois os índios dançavam pulando, como sapos (OLIVEIRA, 2004).

\section{Características do cantar o cururu}

O cururu tradicional pode ser definido como uma dança cantada do caipira paulista, onde vários cantadores em roda versavam sobre temas religiosos, acompanhados de viola, reco-reco e pandeiro (CANDIDO, 1964; VILELA PINTO, 1999; AMARAL PINTO, 2008). A característica de dança se perdeu no estado de São Paulo, esse sumiço pode ter sido em decorrência do processo de urbanização (OLIVEIRA, 2004), o cururu como dança ainda é observado no estado do Mato-Grosso, juntamente com o siriri (outra manifes-tação cultural daquele estado).

Atualmente o cururu tem uma característica de desafio através do canto improvisado entre cantadores (também chamados de canturiões, 
canturinos e trovadores), uma espécie de repente paulista, diferenciando-se do repente nordestino pelo tempo em que os versos são trovados (modo como se chama o cantar no cururu). Enquanto no repente nordestino os ataques e as respostas são rápidos, no cururu eles demoram mais tempo.

0 cururu também pode ser cantado em versos rápidos, denominado assim de "Cana- Verde", onde os canturiões cantam uma estrofe em comum, como: "ai moreninha, moreninha meu amor, nas ondas de seus cabelos corre água e nasce flor", em seguida um cantador elabora um breve verso improvisado, eles cantam a estrofe em comum novamente, vem outro cantador e improvisa rapidamente, por aí em diante.

Antigamente, o tema das trovas era somente o religioso, hoje em dia cantam sobre diversos assuntos. O humor é uma característica marcante, onde um cantador satiriza o outro em seus improvisos, se valendo de diversos artifícios para atingir êxito. Não se sabe exatamente quando o cururu deixou de ser sagrado e se tornou profano, mas sabese que essa característica jocosa do cururu foi acentuada com a difusão deste estilo musical pelas ondas do rádio, atingindo muito sucesso entre a população do interior do estado de São Paulo (OLIVEIRA, 2004).

0 fato é que o público se diverte muito mais quando o cururu é satírico, contribuindo enormemente para que este estilo prevaleça na preferência dos admiradores deste folclore. Apesar de o humor ser uma arma importante dos canturiões existe uma ética entre eles e algumas regras devem ser seguidas na composição das trovas: não se pode satirizar os problemas pessoais reais do "adver-sário", é proibido mexer com família, é preciso respeitar quando o cantador erra uma rima e não abordar temas racistas (muito comuns antiga-mente onde havia disputas de cururu de negros contra brancos mas que está em desuso na atualidade) (GARUTI, 2003).

Os temas religiosos ainda são utilizados como motes para os cantadores elaborarem seus versos, principalmente em eventos como a festa do Divino, a esse fato os cururueiros chamam de "cantar na letra", "cantar na palavra" ou "cantar no livro" (a bíblia). 0 cururu é muito presente nos Pousos do Divino (eventos religiosos onde também ocorre o cururu) que acontecem em inúmeras cidades do interior paulista, principalmente na cidade de Tietê, nestas ocasiões cantar temas bíblicos e religiosos é praticamente uma obrigação.

0 cururu funciona como uma disputa de cantadores entre versos que devem rimar, essa rima que deve ser seguida neste jogo de palavras é chamada de "carreira". Existem diversas carreiras: a do A (palavras terminadas em a), a de São João (palavras terminadas em ão), a do Sagrado (palavras terminadas em ado), a do Divino (palavras terminadas em Ino), a de Santa Clara (palavras terminadas em ara), a do Navio (palavras terminadas em io), dentre outras.

Geralmente as disputas são feitas entre quatro cantadores, duas duplas se desafiando, cada uma representando uma cidade, a reação do público é quem define o "vencedor". Ocorre um sorteio para determinar qual cantador deve iniciar a "trovação", GARUTI nos esclarece como ocorre este processo:

Esse sorteio é feito como as rifas de antigamente: em quatro pedaços de papel são escritos os números de uma a quatro. Os papéis são dobrados de forma igual e colocados dentro de um chapéu. Cada um dos cantadores tira um número. Aquele que pegar o número um, será o primeiro. 0 dois será o segundo e assim por diante. 0 primeiro é o pedestre e é quem deverá iniciar as rimas. 0 número um é parceiro do número três. Os outros números pares são parceiros entre si (2003, p.7).

O cantador inicial é quem determina a carreira que será cantada por todos. Para alguns, iniciar cantando é vantajoso, visto que pode escolher uma carreira complicada, podendo atrapalhar cantadores novatos. Outros acham que ser o pedestre (o primeiro a iniciar a cantoria) é complicado, pois além de testar a aparelhagem técnica do evento, testa também o humor e o gosto da platéia (GARUTI, 2003).

0 canto do cururu deve ser iniciado com o "baixão", uma harmonização vocal (quase sempre sem letra) que serve, além da beleza, para o cantador se preparar no tom em que vai cantar e já iniciar a interação com o violeiro, que deve ajudar cantando neste momento. Alguns cantadores são conhecidos pelos seus "baixões", ao ouvi-los já se sabe quem está cantando.

Posteriormente vem a saudação ao público, no qual o cantador pede licença para iniciar a cantoria, esse procedimento é uma obrigação que o canturião deve seguir no início de sua trovação. A seguir transcrevemos trechos de versos improvisados por Silvio Paes e Zico Moreira (respectivamente) onde eles gentilmente pedem permissão pa-

${ }^{2}$ Em Sorocaba existe a rádio Cacique, que aos domingos tem seu programa de cururu com uma audiência consistente na cidade. Há pouco tempo atrás o cururu ainda era feito ao vivo na rádio, atualmente são reproduzidos programas gravados. 
ra cantar, demonstrando a importância deste momento na cantoria do cururu:

\author{
"Dizer um boa tarde pra todos que aqui \\ estão, \\ Que éo dever de um cantador quando en- \\ trana função \\ Primeiro saudar o povo pra mostrar a \\ educação \\ Então eu quero perguntar pra todos que \\ aqui estão \\ Para o filho e para o pai, eu pergunto co- \\ mo vai e se de saúde vão bão?" \\ "E eu bem sei que encarecia nem falar \\ em permissão \\ Mas meu pai sempre dizia quando eu \\ era rapaizão \\ Quando entrar na cantoria tem que pe- \\ dir autorização \\ Que para um pensador que pensa \\ Cantar sem pedir licença é falta de edu- \\ cação \\ E eu não entro sem pedir licença nem na \\ casa de meu irmão"
}

Após este momento se inicia o ataque aos adversários através dos versos improvisados, cada "golpe" bem realizado é acompanhado de uma vibração da platéia, é uma espécie de "rinha de galo de briga", uma "luta de boxe". Os cantadores se alternam, respondendo e atacando, a empolgação do público afirma quem teve sucesso na disputa. Antigamente as disputas poderiam durar muitas horas inclusive até amanhecer o dia seguinte, atualmente são mais enxutas para que o público possa acompanhar a disputa na integra sem se exaurir no evento.

Quando o cururu gozava de grande prestígio no interior paulista (ou em alguns lugares onde o cururu ainda é muito popular) esses homens possuíam muita fama, atraindo multidões para os locais onde o cururu acontecia. A cidade parava para ouvir os canturiões que encantavam a plateia com suas rimas improvisadas. Inúmeros cantadores de cururu fizeram história, sendo lembrados até hoje pelos lugares onde cantaram.

Um renomado cantador piracicabano marcou época e estilo de cantar, com humor ácido e improvisos rápidos Parafuso, ou Negrinho Parafuso, como era conhecido, é tido como um dos maiores cantadores de cururu de todos os tempos tanto que ficou imortalizado com uma canção no disco da dupla Tião Carreiro e Pardinho, no Lp chamado "No som da viola". A música intitulada "Negrinho Parafuso" teve a letra feita pelo canturião Nhô Chico que homenageou o amigo com seus versos que contavam brevemente sua história e as cidades que com seus versos encantou.

\section{NEGRINHO PARAFUSO}

Havia uma velha casa, perto da linha Fepasa, antiga sorocabana, Lembrança que ainda resta de quem foi o rei das festas das noites interioranas,

Era ele um trovador, renomado cantador de versos improvisados,

Por esse interior afora muita gente ainda chora o Parafuso afamado,

Vivia aquele negrinho rodeado de carinho todos lhe queriam bem, Quando o povo lhe cercava Parafuso não negava um sorriso pra ninguém, No lugar que ele cantava o povão aglomerava para ouvir seu repente Além de bom repentista era também humorista divertia toda gente, Na cidade ou na fazenda onde houvesse uma contenda era sempre convidado,

Das pousadas do divino velhos moços e meninos amanheciam acordados, Tietê, Capivarí, Sorocaba, Tatuí, Laranjal, Botucatu,

Em qualquer localidade era ele na verdade o Pelé do cururu,

Depois de tantas viagens, tantas noites na friagem, Parafuso adoeceu, Nem mesmo estando doente ele cantava contente e nunca se retrocedeu, Mais um dia eu me lembro naquele dois de dezembro a sua hora chegou, A região toda chorava quando o rádio anunciava a morte do cantador, Naquela tarde chuvosa uma multidão chorosa cabisbaixa encontristada, Carregava seu artista o maior dos repentistas para derradeira morada, No mundo tudo se acaba a linda Piracicaba perdeu mais um trovador, O negrinho idolatrado que também foi convocado para seleção do Senhor.

Outros nomes também tem bastante prestígio no ambiente do cururu, citaremos alguns e suas respectivas cidades. Em Sorocaba: Dito Carrara, Cido Garoto, João Davi, Silvio Paes, Dito Silva, Zico Moreira, Dito Boqueirão e Narcizo Correia. Em Piracicaba: Nhô Chico, Nhô Serra, João Mazero, Moacir Siqueira, Parafuso. Tatuí: Jonata e Horácio Neto (irmãos) e Luizinho Rosa. Capivari: Pedro Chiquito.Muitos destes cantadores já faleceram e raros talentos vem surgindo no cenário do cururu, fator preocupante para a manutenção desta manifestação folclórica. 
A viola caipira é o principal instrumento de acompanhamento da cantoria do cururu que pode ter também violão e alguns instrumentos percussivos como o pandeiro e o reco-reco. 0 violeiro de cururu deve ser habilidoso e atento a ponto de acelerar ou retardar o ritmo musical de acordo com a velocidade que o canturião está cantando, às vezes o cantador enrosca em uma palavra ou usa uma mais longa e o violeiro, atento, deve acompanhar tal variação. Não é qualquer violeiro que está apto para tal função, a interação entre canturião e violeiro deve ser plena para o sucesso do evento. Existem grandes violeiros que dominam a técnica de acompanhar com maestria os cantadores de cururu como os sorocabanos Abílio Rosa e Carlos Caetano, e os piracicabanos Milo da Viola e Toninho da Viola.

\section{Geografia, lugar e música}

Na sua experiência cotidiana com o meio em que habita o ser humano desenvolve pelo espaço muito mais do que uma relação funcional e lógica. Desenvolve, sobretudo, uma relação subjetiva e intersubjetiva, que envolve sentimentos e imaginários.

Esta relação íntima e orgânica com o espaço é denominada de lugar, o espaço de vivência primordial dos homens, é onde, verdadeiramente existimos e construímos nossa vida, é o espaço do diaa-dia, do cotidiano, nossa verdadeira geografia, "é o ponto de partida da experiência geográfica [...] onde as bases de nossa existência mundana e da nossa condição humana se estabelecem" (DARDEL apud RELPH, 1979, p.16).

O lugar é um conceito muito importante para a Geografia, e recebe uma atenção especial na Geografia Humanista (vertente que tem na fenomenologia uma de suas bases filosóficas e alicerce na apreensão da relação do homem com o mundo) que analisa o espaço pela dimensão da experiência humana. Aqui o conceito extrapola a noção simplista de localização, ele está associado com a relação existencial que os homens constroem com os lugares, como afirma TUAN:

O lugar, no entanto, tem mais substância do que nos sugere apalavra localização: ele é uma entidade única, um conjunto 'especial', que tem história e significado. 0 lugar encarna as experiências e aspirações das pessoas. 0 lugar não é só um fato a ser explicado na am- pla estrutura do espaço, ele é a realidade a ser esclarecida e compreendida sob a perspectiva das pessoas que lhe dão significado (TUAN apud HOLZER, 1999, p.70).

A relação com os lugares pode ser topofílica ou topofóbica. Chamamos de Topofilia a relação agradável e confortável com o lugar, e de Topofobia o oposto, ou seja, uma relação desagradável. Estes termos foram cunhados por Gastón Bachelard e desenvolvidos na Geografia por Yi-Fu Tuan (RELPH, 1979). Nossas sensações e sentimentos em relação a um mesmo lugar podem variar:

Topofobia, como topofilia, está associada com o caráter das paisagens e dos espaços, e com as atitudes daqueles experienciando a paisagem. Isso significa que, como a aparência de um lugar particular se altera, também nossas atitudes e modos se modificam, de maneira que nossa experiência pode variar de topofílica a topofóbica e vice-versa (RELPH, 1979, p.21).

Este pertencimento do homem ao seu meio pode ser percebido nas manifestações artísticas, como na música, pois a entendemos como fruto da relação direta do homem com seu lugar, uma revelação do seu habitar ${ }^{3}$. Esta afinidade é permeada por sentimentos (paixão, angústia, saudade, tristeza e felicidade) temas tão frequen-tes na música caipira e nos versos dos cururueiros do médio Tietê.

Na música caipira, bem como nas trovas de cururu podemos perceber a íntima relação do homem com o lugar: a saudade da terra natal e da casinha de criação, da paisagem local, os cheiros, as cores e o cotidiano que tanto alimentam a mente do cantor. A seguir transcrevemos um verso do cururueiro piracicabano João Mazeiro para exemplificar esta relação com o lugar expressa na música (a maneira caipira de se pronunciar as palavras foi mantida nesta transcrição):

"Viola linda viola, que veio lá do sertão No peito de dois violeiro, afinada em cebolão

E o Roque no reco-reco, ai meu povo, certinho na marcação.

Hoje eu moro na cidade, mas tenho recordação

Do meu tempinho do sítio, meu Deus

${ }^{3}$ O habitar na Geografia Humanista está embasado no conceito de dwelling do filósofo Martin Heidegger e “[...] implica mais do que morar, cultivar ou organizar o espaço. Significa viver de um modo pelo qual se está adaptado aos ritmos da natureza, ver a vida da pessoa como apoiada na história humana e direcionada para um futuro, construir um lar que é símbolo de um diálogo diário com o meio ambiente ecológico e social da pessoa" (BUTTIMER, 1982, p.166). 
que tempinho bom

Papai fazia lavoura, ai meu povo, cuidava da plantação.

Nóis tinha uma casa grande, na frente um terreirão

Onde secava o café, também maiava o feijão

E ao lado uma laranjeira, ai meu povo, e vários pé de limão.

No canto uma taiuveira, sempre pousava um gavião

Lá do alto da cachoeira, nas costa de um espigão

Vinha o sabiá coleira, ai meu povo, canta no pé de mamão.

Na serra uma vertente, que descia num grotão

Quando chegava na frente, formava um ribeirão

No domingo de calor, minha gente, nadava com meus irmão "

Nestes versos aqui transcritos é clara a íntima ligação do canturião com seu lugar de criação. A casa no sítio e os elementos de sua paisagem são descritos com imensa clareza e ternura em seus versos a tal ponto que nos possibilita visualizar como seria este "pedaço" de terra tão importante para o cantor. Apesar de viver na cidade e do tempo transcorrido, João Mazeiro não esquece seu lugar de infância e sua relação familiar com ele.

Este é um exemplo de um verso de cururu onde a relação topofílica é descrita pelo canturião, porém, o fato é corriqueiro no cururu e na música caipira em geral, pois o lugar constantemente é lembrado e exaltado pelos cantadores.

\section{Conclusão}

É notável o esforço dos geógrafos em buscar novos temas e maneiras de compreender a Geografia, visto que esta é complexa e repleta de nuanças. Diversos assuntos que antes não eram considerados no campo desta ciência vêm sendo estudados. A música é um destes temas, porém, temos poucos trabalhos que procuram aliar música e Geografia, principalmente aqui no Brasil. Esta renovação temática é muito importante, pois, possibilita rever e aprofundar conceitos importantes da Geografia através de outros ângulos.

Procurar compreender o espaço geográfico através da música nos abre novas possibilidades de análise da relação do homem com o meio, permitindo que avancemos no corpo teórico e prático de nossa disciplina.

Entendemos que este tipo de trabalho também seja importante no sentido em que valoriza culturas locais. Esse tipo de manifestação artística e folclórica é fundamental para o sentido de pertencimento a um lugar. Isto é essencial para o ser humano se sentir seguro, acolhido no espaço em que vive (na verdade tornando espaço em lugar (TUAN, 1983)), ainda mais nos tempos atuais em que somos bombardeados pelos diversos meios de comunicação com "culturas" que nem sempre nos são pertencentes e que pouco ou quase nada nos acrescentam.

Este cenário pode deixar o homem desnorteado, sem chão, sem uma referência sobre si mesmo e sobre o lugar em que vive, é neste contexto que o trabalho pretende fazer um resgate das raízes da cultura caipira e do cururu, propondo uma revalorização das identidades locais, consequentemente, uma revalorização do homem e de sua manifestação através da música.

\section{Referências}

ABREU, Martha Campos. Histórias da Música Popular Brasileira, uma análise da produção sobre período Colonial, 2001. Disponível em: http://www.historia uff.br/nupehc/files/martha.pdf. Acessado em: 10/03/2011.

AMARAL PINTO, João Paulo. A viola caipira de Tião Carreiro. Dissertação (Mestrado em Artes) - Universidade Estadual de Campinas, Instituto de Artes. Campinas, 2008.

ANASTÁCIO, Ricardo. História, Método e Ponteados da Viola Caipira do Médio Tietê: Nheengatu- a Identidade Caipira. Sorocaba: Edição do autor, 2010.

ARAÚJO, Alceu Maynard. Viola Cabocla. In Revista Sertaneja números 4, 5, 6, 7, 8, 9, 13 e 14, de julho de 1958 a $\mathrm{m}$ a i o d e 1959 . D i s p o níve l e m : http://www.widesoft.com.br/users/pcastro4/viola.ht m. Acessado em: 23/02/2011.

BUTTIMER, Anne. Apreendendo o dinamismo do mundo vivido.In: CHRISTOFOLETTI, Antonio. Perspectivas da geografia. Rio Claro, SP: Difel, 1985.

CANDIDO, Antonio. Os parceiros do Rio Bonito: estudo sobre o caipira paulista e a transformação dos seus meio de vida. São Paulo: Ed.34, 2001.

CAVALHEIRO, Carlos Carvalho. In: Cururu: Retratos de uma Tradição. Sorocaba, SP: Crearte Editora, 2003.

CUNHA, Euclydes Da. Os Sertões: campanha de Canudos. Rio de Janeiro: Livraria Francisco Alves Editora; $\mathrm{Pu}$ - 
ENTRIKIN, J. Nicholas. O Humanismo Contemporâneo em Geografia. Boletim de Geografia Teorética. Rio Claro, v. 10, n. 19, p. 05-30, 1980

GARUTI, Aparecido. Cururu: Retratos de uma Tradição. Sorocaba, SP: Crearte Editora, 2003.

HOLLER, Marcos. A Música na Atuação dos Jesuítas na América Portuguesa. 2005, Disponível em: http: / / www.an p pom.com.br/anais / a nais congresso_anppom_2005/sessao19/marcos_holler.pdf. Acessado em: 10/03/2011.

HOLZER, Werther. O lugar na Geografia Humanista. Revista Território. Rio de Janeiro, ano IV, Jul. Dez., p.67-78, 1999.

NEPOMUCENO, Rosa. Música Caipira: Da Roça ao Rodeio. São Paulo: Editora 34,1999.

OLIVEIRA, Allan de Paulo. 0 Tronco da Roseira: uma antropologia da viola caipira. Dissertação apresentada ao programa de Pós-Graduação em Antropologia Social da Universidade Federal de Santa Catarina. UFSC, 2004.

RELPH, E. C. As Bases Fenomenológicas da Geografia. Geografia. Rio Claro, v. 04, n. 07, abril, p. 01-25, 1979

RIBEIRO, José Hamilton. Música Caipira: as 270 maio-
TUAN, Yi-Fu. Espaço e lugar: a perspectiva da experiência. (trad. Lívia de Oliveira) São Paulo: Difel, 1983.

VILELA PINTO, Ivan. Do Velho se Faz o Ovo. Dissertação (Mestrado em Artes) - Universidade Estadual de Campinas, Instituto de Artes. Campinas, 1999.

\title{
Manifestation of the place in cururu's verses of mid-Tietê Paulista's region
}

\begin{abstract}
To analyze the relationship between man and the place and how this affinity is expressed in music, is the primary intention of this work that is part of a project of postgraduate studies. The phenomenological bias in Geography will be guiding this process. The spatial area is the interior of São Paulo (more precisely the region of the mid-Tietê) and manifestation through cururu. The folk cururu is a typical manifestation of some cities in this region and consists of a dispute between singers that deal with various topics to the sound of the viola. We hope that this work gives some contribution to the dialogue between geography and music, as well as revalue regional cultural event, so important to the identity of the people who live.

Keywords: Geography. Place. Cururu.
\end{abstract}

\section{La expresión del lugar en los versos del cururu en la región paulista del Medio-Tietê}

\footnotetext{
Resumen: Analizar la relación entre el hombre y el lugar y cómo esta afinidad se expresa en la música es la intención principal de este trabajo que es parte de un proyecto de pós-grado. La tendencia fenomenológico en Geografía será guiará este proceso. El área espacial es el interior de São Paulo (más precisamente la región del medio Tietê) y la manifestación a través del cururu. El cururu una es manifestación folclórica típica de algunas ciudades de esta región y se compone de una disputa entre los cantantes que se ocupan de diversos temas con el sonido de la viola. Cabe esperar que este trabajo contribuye al diálogo entre la geografía y la música, así como la revalorización regional de manifestación cultural, tan importante para la identidad de las personas que viven.

Palabras-clave: Geografia. Lugar. Cururu.
} 